\title{
Effects of treatment with long-acting muscarinic antagonists (LAMA) and long-acting beta-agonists (LABA) on lung function improvement in patients with bronchiectasis: an observational study
}

\author{
Su Yeon Lee, Jae Seung Lee, Sei Won Lee, Yeon-Mok Oh \\ Department of Pulmonary and Critical Care Medicine, Asan Medical Center, University of Ulsan College of Medicine, Seoul, Korea \\ Contributions: (I) Conception and design: All authors; (II) Administrative support: SY Lee, YM Oh; (III) Provision of study materials or patients: SY \\ Lee, YM Oh; (IV) Collection and assembly of data: SY Lee; (V) Data analysis and interpretation: All authors; (VI) Manuscript writing: All authors; (VII) \\ Final approval of manuscript: All authors. \\ Correspondence to: Yeon-Mok Oh. Department of Pulmonary and Critical Care Medicine, Asan Medical Center, University of Ulsan College of \\ Medicine, 88, Olympic-ro 43-gil, Songpa-gu, Seoul 05505, Korea. Email: ymoh55@amc.seoul.kr.
}

Background: Patients with bronchiectasis are often treated with bronchodilators such as long-acting muscarinic antagonists (LAMA) or long-acting beta-agonists (LABA) for their symptoms, but empirical evidence supporting such practice is sparse. We evaluated the effect of LAMA and LABA on lung function improvement in patients with bronchiectasis.

Methods: Using the in-house patient database at a tertiary referral hospital in Seoul, South Korea, we extracted data from patients diagnosed as bronchiectasis with computed tomography (CT) scan and treated with LAMA, LABA, or both. Patients with asthma, chronic obstructive pulmonary disease (COPD) or a history of cigarette smoking were excluded, and a subgroup analysis was performed in patients who did not receive concurrent treatments such as antibiotics, mucolytics or systemic steroids that may affect lung function improvement.

Results: A total of 230 patients (males: $32.6 \%$, median age: 60 years) were analyzed. Their mean forced expiratory volume in 1 second $\left(\mathrm{FEV}_{1}\right)$ was $53.3 \%$ of the predicted value [standard deviation (SD), 15.3]. The patients received LAMA ( $\mathrm{n}=95)$, LABA ( $\mathrm{n}=36)$, or both (LAMA-LABA; $\mathrm{n}=99)$, after which their FEV $\mathrm{V}_{1}$ values were increased by 0.102 liters (SD, 0.208; $\mathrm{P}<0.001)$, 0.133 liters (SD, 0.181; $\mathrm{P}<0.001)$, and 0.122 liters (SD, $0.230 ; \mathrm{P}<0.001)$, respectively. In a subgroup of 97 patients who did not receive concurrent treatments, the $\mathrm{FEV}_{1}$ was increased by with 0.107 liters (SD, 0.167; $\left.\mathrm{P}<0.001\right), 0.165$ liters (SD, 0.209; $\left.\mathrm{P}=0.005\right)$, and 0.165 liters (SD, 0.187; $\mathrm{P}<0.001$ ) in the LAMA, LABA, and LAMA-LABA groups, respectively. Baseline FEV had a significant negative correlation with response to bronchodilator treatment in the total patient cohort $(\mathrm{R}=-0.242, \mathrm{P}<0.001)$ and the subgroup of patients without concurrent treatments $(\mathrm{R}=-0.386, \mathrm{P}<0.001)$.

Conclusions: Treatment with bronchodilators such as LAMA or LABA was effective in improving lung function in patients with bronchiectasis, regardless of concurrent treatments that also improve lung function. These data may support the use of LAMA and LABA in patients with bronchiectasis.

Keywords: Bronchiectasis; long-acting muscarinic antagonists (LAMA); long-acting beta-agonists (LABA); forced expiratory volume in 1 second $\left(\mathrm{FEV}_{1}\right)$

Submitted Mar 11, 2020. Accepted for publication Aug 28, 2020.

doi: $10.21037 /$ jtd-20-1282

View this article at: http://dx.doi.org/10.21037/jtd-20-1282

(C) Journal of Thoracic Disease. All rights reserved. 


\section{Introduction}

Bronchiectasis is a chronic lung disease characterized by cough, sputum, and repeated bronchial infections with permanent bronchial dilatation (1). Bronchiectasis is a particularly important disease entity in South Korea because its overall prevalence is higher than those in other countries $(2,3)$. Approximately $18 \%$ of patients with bronchiectasis require hospitalization, and the in-hospital all-cause mortality is $2.9 \%$ (2).

In bronchiectasis, inflammation and chronic bronchial infections cause airway structural changes, and more than $50 \%$ of patients have airflow obstructions as a result (1). Poor lung function is a predictor of exacerbation and also an indicator of deterioration in patients with bronchiectasis $(4,5)$. Although current practice guidelines suggest using bronchodilators such as long-acting muscarinic antagonists (LAMA) or long-acting beta-agonists (LABA) in bronchiectasis patients with low lung functions, empirical evidences for supporting such guidelines are sparse (6). We thus evaluated the effectiveness of LAMA and LABA in improving the lung function of patients with bronchiectasis.

\section{Methods}

\section{Study design and patients}

This was a retrospective, observational study comparing the lung functions in patients with bronchiectasis before and after long-acting bronchodilator treatment to evaluate the effectiveness of LAMA and LABA. We gathered data on adult patients with bronchiectasis (age $\geq 18$ ) who were prescribed LAMA, LABA, or both between January 2008 and December 2018 at Asan Medical Center, a tertiary referral hospital in Seoul, Korea. We extracted data from patients diagnosed as bronchiectasis with CT scan and we excluded patients diagnosed with asthma or chronic obstructive pulmonary disease (COPD) who have been found to benefit from using long-acting bronchodilators (7); moreover, we excluded patients with a history of cigarette smoking, even 1 pack year, which is the most important cause of COPD in South Korea (8). We also performed a subgroup analysis by excluding patients who received concurrent treatment such as antibiotics, systemic steroids, or mucolytics, all of which affect lung function by improving mucociliary clearance and reducing chronic bronchial infection and inflammation $(1,5)$.

\section{Data extraction}

Patient data were extracted from the electronic medical records by using the in-house data extraction program at Asan Medical Center. We obtained baseline characteristics including age, sex, body mass index (BMI), and modified Medical Research Council (mMRC) dyspnea grade at the time of the first prescription of bronchodilator. In addition, comorbidities of pulmonary and extra-pulmonary disease and the type of prescribed bronchodilators were identified.

\section{Lung function}

Lung function before and after bronchodilator treatment were compared. For the lung function data from before the treatment, we used the data closest to the index date and obtained within 6 months from the index date; the index date was defined as the date of the first prescription of LAMA or LABA. For the lung function data after the treatment, we used the lung function data, closest to 6 months after treatment, and among at least 1 to 12 months after treatment. Spirometry was checked by the Vmax Series (CareFusion Corporation, Yorba Linda, CA, USA) according to the recommendation by the American Thoracic Society/ European Respiratory Society (9). We used FEV 1, FVC and $\mathrm{FEV}_{1} / \mathrm{FVC}$ but didn't use the short-acting bronchodilator response of those. We used the reference equation of spirometry derived from a representative sample of the Korean population (10).

\section{Long-acting bronchodilator treatment}

All patients were treated with LAMA, LABA, or both for at least 1 month. The patients in the LAMA group were prescribed tiotropium, and those in the LABA group were prescribed one of the five kinds of LABA: indacaterol, salmeterol/fluticasone, formoterol/budesonide, formoterol/ beclomethasone, and vilanterol/fluticasone. The LAMALABA group were prescribed 1 of the 3 combinations of LAMA and LABA: tiotropium/olodaterol, umeclidinium/ vilanterol, and glycopyrronium/indacaterol. To measure the medication adherence, we calculated the medication possession ratio in all patients (11-14). Each patient received specific instructions on the correct use of devices by a trained coordination nurse. 


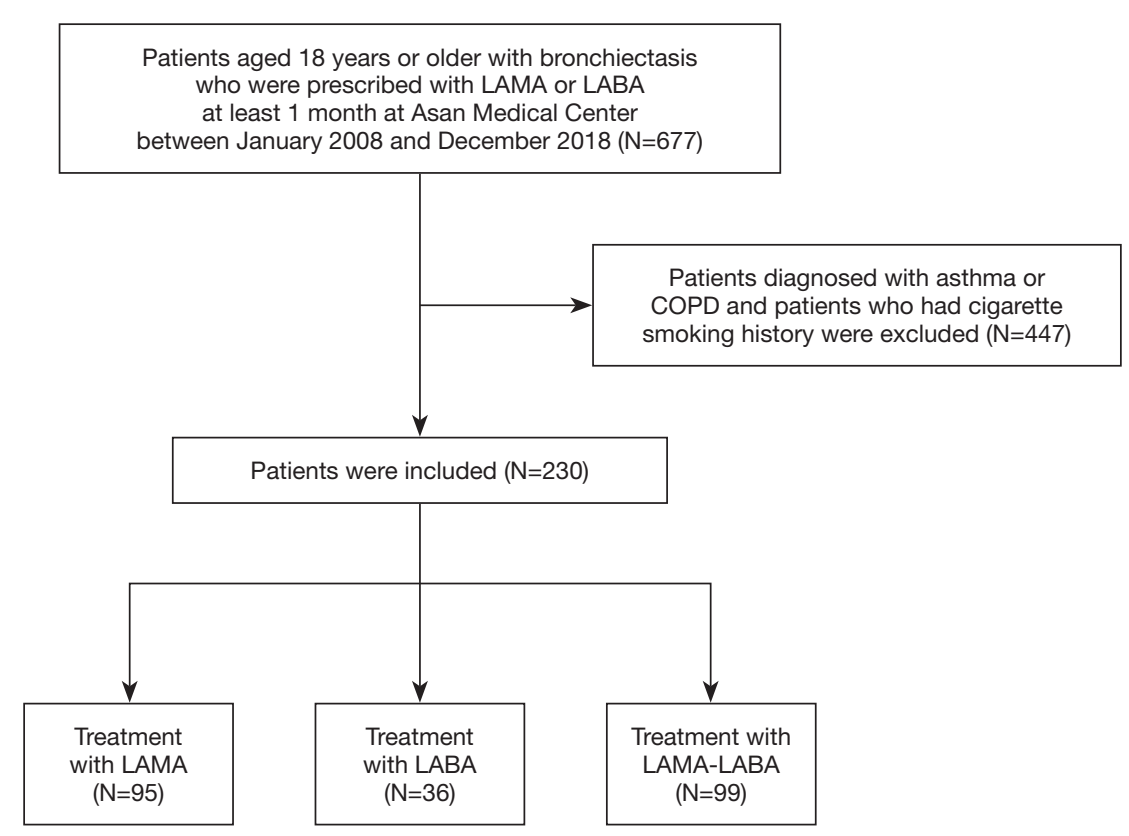

Figure 1 Patient selection flow. LAMA, long-acting muscarinic antagonist; LABA, long-acting beta-agonists; COPD, chronic obstructive pulmonary disease.

\section{Statistical analysis}

Paired Student's $t$-test was used to compare the lung functions of each patient before and after treatment. Linear regression analysis was performed to identify the factors related to the effects of bronchodilators in lung function. Pearson's correlation analysis was used to determine the correlation between baseline $\mathrm{FEV}_{1}$ (\% predicted) and the changes in $\mathrm{FEV}_{1}$ (liter) after treatment. All statistical analyses were performed using the SPSS 21.0 software (IBM Corporation, Armonk, NY, USA) and the graphs were drawn using the SPSS 21.0 and the $\mathrm{R}$ studio software ( $\mathrm{R}$ studio, Inc., Boston, MA, USA).

\section{IRB and informed consent}

The study was conducted in accordance with the Declaration of Helsinki and the Harmonized Tripartite Guideline for Good Clinical Practice from the International Conference on Harmonization. The Institutional Review Board (IRB) of Asan Medical Center approved this study's protocol (\#2019-0122) and waived the need for written informed consent based on the retrospective nature of the study.

\section{Results}

\section{Characteristics of the patients}

We analyzed a total of 230 patients after applying the predefined inclusion/exclusion criteria (Figure 1). The median age of the patients was 60 years, and $32.6 \%$ were male (Table 1). Most patients only had mild dyspnea or did not suffer from dyspnea [mMRC dyspnea grade $0-1, \mathrm{n}=199$ $(86.5 \%)]$. A total of $45(19.6 \%)$ patients had a history of tuberculosis infection and $22(9.6 \%)$ patients had current or past non-tuberculous mycobacterial infection. The baseline mean $\mathrm{FEV}_{1}$ was $1.38 \pm 0.46 \mathrm{~L}(53.3 \% \pm 15.3 \%$ of predicted value), the FVC was $2.30 \pm 0.71 \mathrm{~L}(67.3 \% \pm 15.9 \%$ of predicted value), and the $\mathrm{FEV}_{1} / \mathrm{FVC}$ was $0.61 \pm 0.12$.

\section{Effect of LAMA, LABA, or both on lung function in bronchiectasis patients}

Among the 230 patients, 95 (41.3\%) patients were treated with LAMA for a median duration of 147 days [interquartile range (IQR), 85-210 days], 36 (15.7\%) patients were treated with LABA for a median duration of 121 days (IQR, 84-194.5 days), and 99 patients were treated with both LAMA and LABA for a median duration of 140 days (IQR, 
Table 1 Baseline characteristics of the study patients

\begin{tabular}{|c|c|c|c|c|}
\hline Characteristics & All patients & $\begin{array}{l}\text { Treatment with } \\
\text { LAMA }\end{array}$ & $\begin{array}{l}\text { Treatment with } \\
\text { LABA }\end{array}$ & $\begin{array}{l}\text { Treatment with } \\
\text { LAMA-LABA }\end{array}$ \\
\hline Number of patients & 230 & 95 & 36 & 99 \\
\hline Male sex & $75(32.6)$ & $33(34.7)$ & $12(33.3)$ & $30(30.3)$ \\
\hline 0 & $115(50.0)$ & $46(48.4)$ & $23(63.9)$ & $46(46.5)$ \\
\hline 1 & $84(36.5)$ & $42(44.2)$ & $7(19.4)$ & $35(35.4)$ \\
\hline 2 & $26(11.3)$ & $6(6.3)$ & 5 (13.9) & $15(15.2)$ \\
\hline Past tuberculosis infection & 45 (19.6) & $20(21.1)$ & $6(16.7)$ & $19(19.2)$ \\
\hline Past or current NTM infection & $22(9.6)$ & $8(8.4)$ & $3(8.3)$ & $11(11.1)$ \\
\hline \multicolumn{5}{|l|}{ Extrapulmonary comorbidities } \\
\hline Hypertension & $74(32.2)$ & $27(28.4)$ & $13(36.1)$ & $34(34.3)$ \\
\hline Diabetes mellitus & $30(13.0)$ & $10(10.5)$ & $6(16.7)$ & $14(14.1)$ \\
\hline Cardiocerebrovascular disease & $15(6.5)$ & $4(4.2)$ & $2(5.6)$ & $9(9.1)$ \\
\hline Chronic kidney disease & $7(3.0)$ & $1(1.1)$ & $1(2.8)$ & $5(5.1)$ \\
\hline $\mathrm{FEV}_{1} / \mathrm{FVC}$ & $0.61 \pm 0.12$ & $0.64 \pm 0.01$ & $0.66 \pm 0.14$ & $0.56 \pm 0.12$ \\
\hline
\end{tabular}

Data are presented as numbers (\%) unless specified otherwise. ${ }^{a}$, median (interquartile range); ${ }^{\mathrm{b}}$, mean \pm standard deviation. mMRC,

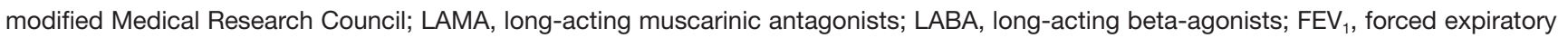
volume in 1 second; FVC, forced vital capacity.

91-210 days). The medication possession ratio was $89.2 \%$. Of the 36 patients in the LABA group, five were prescribed LABA alone, while 31 were prescribed LABA and inhaled corticosteroids. After receiving treatment, the $\mathrm{FEV}_{1}$ was increased by 0.102 liters [standard deviation (SD), 0.208; $\mathrm{P}<0.001$ ], 0.133 liters (SD, 0.181; $\mathrm{P}<0.001$ ), and 0.122 liters (SD, 0.230; $\mathrm{P}<0.001)$ in the LAMA, LABA, and LAMALABA groups, respectively (Figure 2).

\section{Subgroup analysis after excluding patients treated with other medications}

We performed a subgroup analysis by excluding patients who were concurrently treated with antibiotics, systemic steroids, or mucolytics (Table S1, Figure S1). In the remaining 97 patients without concurrent treatments, the $\mathrm{FEV}_{1}$ was increased by with 0.107 liters (SD, 0.167; $\mathrm{P}<0.001), 0.165$ liters (SD, 0.209; $\mathrm{P}=0.005$ ), and 0.165 

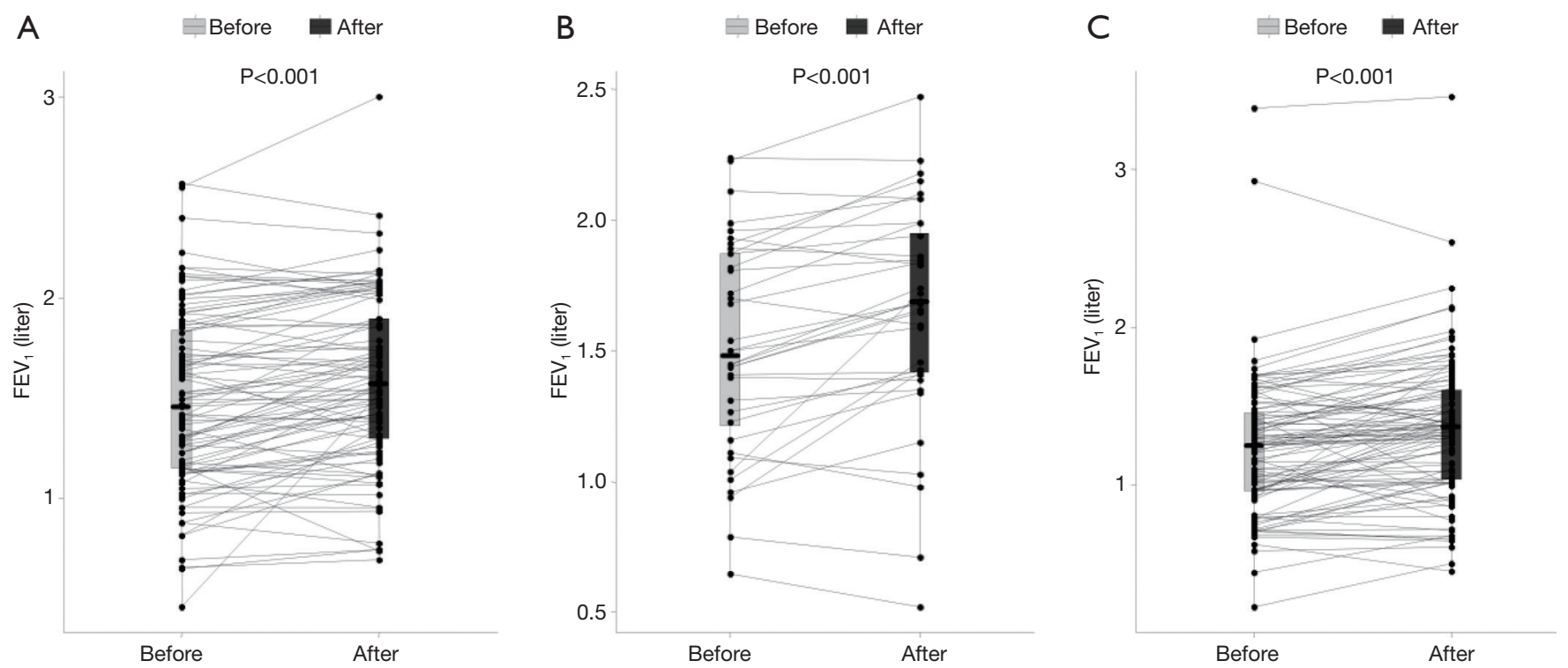

Figure 2 Changes in $\mathrm{FEV}_{1}$ after treatment with LAMA (N=95) (A), LABA (N=36) (B), or LAMA-LABA (N=99) (C). FEV ${ }_{1}$, forced expiratory volume in 1 second; LAMA, long-acting muscarinic antagonist; LABA, long-acting beta-agonists.
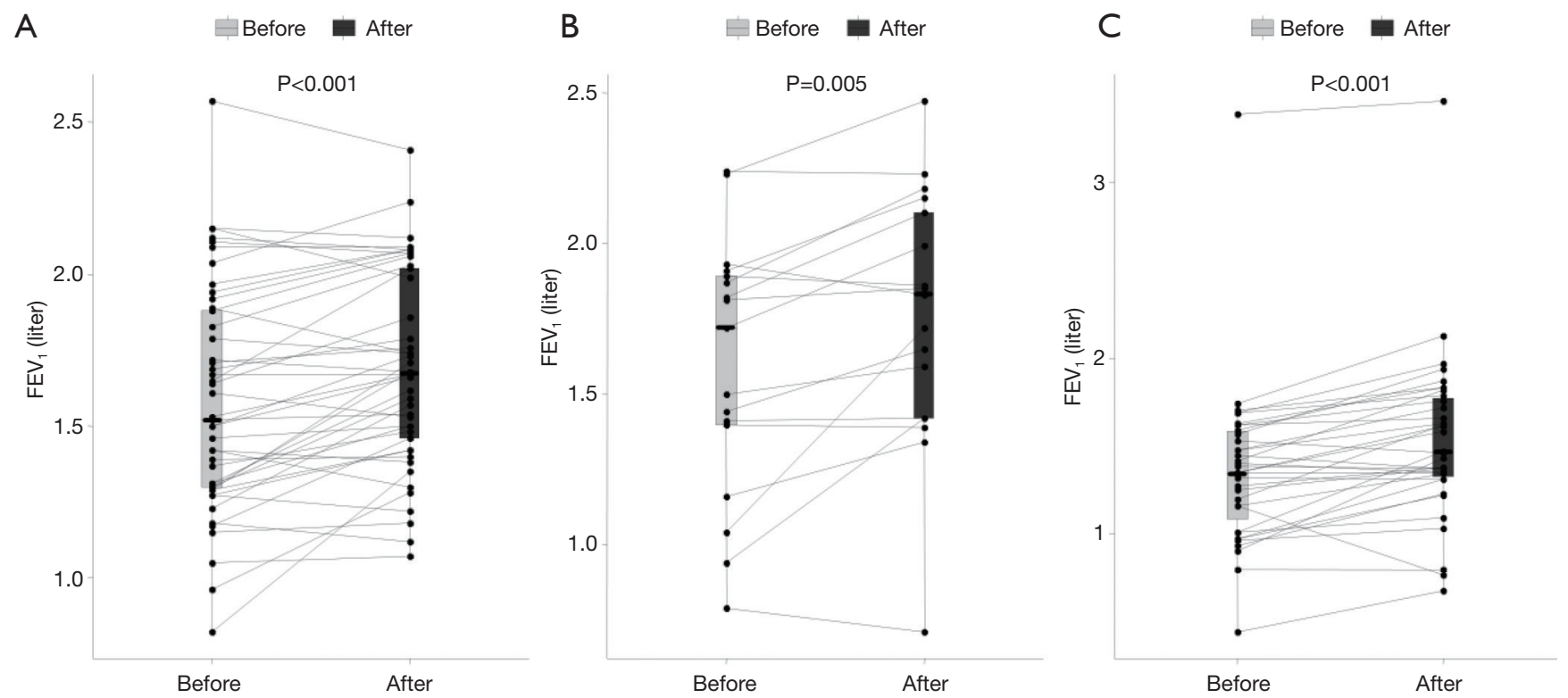

Figure 3 Changes in $\mathrm{FEV}_{1}$ in patients without concurrent treatments after treatment with LAMA (N=45) (A), LABA (N=17) (B), or LAMALABA $(\mathrm{N}=35)(\mathrm{C}) . \mathrm{FEV}_{1}$, forced expiratory volume in 1 second; LAMA, long-acting muscarinic antagonist; LABA, long-acting betaagonists.

liters $(\mathrm{SD}, 0.187 ; \mathrm{P}<0.001)$ in the LAMA, LABA, and LAMA-LABA groups, respectively (Figure 3). Of the 106 patients who received antibiotics in the follow-up period, 18 had been newly started on long-term antibiotics, such as azithromycin, roxithromycin, erythromycin, and clarithromycin, during the follow-up period, and the remaining 88 patients had been prescribed short-term antibiotics because of pneumonia or worsening of clinical symptoms in the outpatient or inpatient clinic. We excluded both groups of patients. 
Table 2 Factors associated with the response of $\mathrm{FEV}_{1}$ to bronchodilator treatment $(\mathrm{N}=230)$

\begin{tabular}{|c|c|c|c|c|c|c|}
\hline Factors & \multicolumn{3}{|c|}{ Univariate } & \multicolumn{3}{|c|}{ Multivariate } \\
\hline Age & -0.001 & $-0.004,0.01$ & 0.254 & 0.0001 & $-0.002,0.003$ & 0.901 \\
\hline Male sex & -0.026 & $-0.85,0.034$ & 0.394 & -0.035 & $-0.093,0.023$ & 0.241 \\
\hline \multicolumn{7}{|l|}{ mMRC dyspnea grade } \\
\hline mMRC 0-1 (low) & 0.035 & $-0.046,0.116$ & 0.396 & - & - & - \\
\hline mMRC 2-4 (high) & -0.035 & $-0.116,0.046$ & 0.396 & - & - & - \\
\hline Past tuberculosis infection & 0.058 & $-0.011,0.128$ & 0.099 & 0.053 & $-0.16,0.121$ & 0.133 \\
\hline Chronic kidney disease & -0.007 & $-0.169,0.155$ & 0.934 & - & - & - \\
\hline $\begin{array}{l}\text { Cardiocerebrovascular disease, } \\
\text { other than hypertension }\end{array}$ & -0.006 & $-0.118,0.107$ & 0.923 & - & - & - \\
\hline Baseline $\mathrm{FEV}_{1}$ & -0.003 & $-0.005,-0.002$ & $<0.001$ & -0.003 & $-0.005,-0.001$ & 0.001 \\
\hline
\end{tabular}

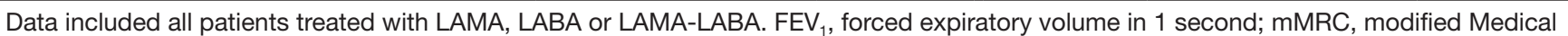
Research Council; NTM, nontuberculous mycobacteria; LAMA, long-acting muscarinic antagonists; LABA, long-acting beta-agonists.

\section{Factors associated with the response of FEV $V_{1}$ to bronchodilator treatment}

In the 230 patients, linear regression analysis showed that baseline $F E V_{1}$ had a significant negative correlation with response to bronchodilator treatment $(\mathrm{R}=-0.242, \mathrm{P}<0.001$; Table 2, Figure S2A). Likewise, in the subgroup of 97 patients without concurrent treatments, baseline $\mathrm{FEV}_{1}$ had a significant negative correlation with response to treatment $(\mathrm{R}=-0.386, \mathrm{P}<0.001$; Table 3, Figure S2B $)$.

\section{Discussion}

In this retrospective study, we found that bronchodilator treatment with LAMA, LABA, or both was effective in improving the lung function in patients with bronchiectasis, most of whom did not suffer from severe dyspnea but had poor lung functions. Lower baseline $\mathrm{FEV}_{1}$ was significantly associated with better response to bronchodilator treatment. These results were also confirmed in a subgroup analysis after excluding patients concurrently treated with antibiotics, mucolytics, or systemic steroids, thus signifying the sole beneficial effect of LAMA, LABA, or both in patients with bronchiectasis.

In the general population, lung function deteriorates over time with an annual $\mathrm{FEV}_{1}$ decline rate of $25-30 \mathrm{~mL} /$ year at ages $35-40$, and $60 \mathrm{~mL} /$ year after 70 years of age $(15,16)$. In this study, we observed the $\mathrm{FEV}_{1}$ increased over $100 \mathrm{~mL}$ in patients treated with LAMA, LABA or both. Therefore, we found that treating with long-acting bronchodilator was significantly effective in patients with bronchiectasis. To date, randomized controlled trials on the effect of LAMA or LABA in patients with bronchiectasis have not been carried out. In patients with destroyed lungs due to tuberculosis, a randomized controlled trial showed that treatment with LABA for eight weeks was effective in improving their lung functions (17). Thus, although our study had an observational design, its results may support the use of LAMA and LABA in patients with bronchiectasis and warrant the need for a randomized controlled trial to solidify such indication.

We found that there is a negative correlation between the baseline value of $\mathrm{FEV}_{1}$ and the improvement of $\mathrm{FEV}_{1}$ 
Table 3 Factors associated with the response of $\mathrm{FEV}_{1}$ to bronchodilator treatment after excluding patients who received concurrent treatments $(\mathrm{N}=97)$

\begin{tabular}{|c|c|c|c|c|c|c|}
\hline Factors & \multicolumn{3}{|c|}{ Univariate } & \multicolumn{3}{|c|}{ Multivariate } \\
\hline Male sex & -0.015 & $-0.092,0.063$ & 0.706 & -0.029 & $-0.101,0.043$ & 0.423 \\
\hline mMRC 0-1 (low) & -0.044 & $-0.156,0.068$ & 0.434 & - & - & - \\
\hline mMRC 2-4 (high) & 0.044 & $-0.068,0.156$ & 0.434 & - & - & - \\
\hline Past tuberculosis infection & 0.041 & $-0.050,0.132$ & 0.372 & - & - & - \\
\hline Chronic kidney disease & 0.009 & $-0.204,0.223$ & 0.933 & - & - & - \\
\hline $\begin{array}{l}\text { Cardiocerebrovascular disease, } \\
\text { other than hypertension }\end{array}$ & 0.148 & $-0.035,0.332$ & 0.122 & - & - & - \\
\hline Baseline FEV 1 & -0.005 & $-0.008,-0.003$ & $<0.001$ & -0.006 & $-0.009,-0.003$ & $<0.001$ \\
\hline
\end{tabular}

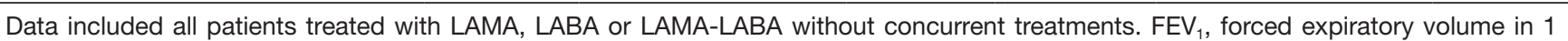
second; mMRC, modified Medical Research Council; NTM, nontuberculous mycobacteria; LAMA, long-acting muscarinic antagonists; LABA, long-acting beta-agonists.

after bronchodilator treatment. In patients with COPD, the increase of $\mathrm{FEV}_{1}$ upon treatment with salbutamol and ipratropium inhalation was significantly associated with the

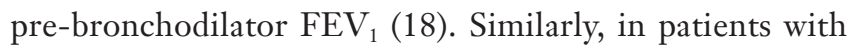
bronchiectasis who received salbutamol administration, bronchodilator response was negatively correlated with baseline $\mathrm{FEV}_{1}$ percentage predicted (19). Another study in patients with COPD who received salbutamol administration also showed that changes in $\mathrm{FEV}_{1}$ were negatively correlated with pre-bronchodilator $\mathrm{FEV}_{1}(20)$. Our current study is meaningful because it is the first to show that the increase of $\mathrm{FEV}_{1}$ is negatively correlated with baseline $\mathrm{FEV}_{1}$ after long term use of LAMA and/or LABA in patients with bronchiectasis. Therefore, these empirical evidences show that the effect of bronchodilators is greater in those with poorer lung function at baseline, and thus support the use of LAMA or LABA in such patients.

Recently, the role of pulmonary rehabilitation therapy in chronic respiratory disease has been emphasized and its effectiveness has been proved in many studies (21). However, the use of pulmonary rehabilitation has only recently begun to emerge in South Korea, and only one of the 230 patients received rehabilitation therapy during the treatment period in our study.

This study has limitations inherent to its retrospective, observational design. First, we could not evaluate the compliance of bronchodilator use during the treatment period and calculated the medication possession ratio instead-the medication possession ratio of our study patients was $89.2 \%$, which may be regarded to indicate adequate adherence (11-14). Also, observational study design is not suitable for determining the long-term effectiveness of an intervention because the effects of confounding factors cannot be adequately excluded (22). To partially compensate for such limitations, we performed a subgroup analysis after excluding patients who received other treatments that may affect lung function and found that the results were in line with those from the entire cohort.

We excluded patients with a smoking history in addition to those diagnosed with COPD in order to exclude potential COPD more broadly. However, after we reviewed the CT 
scans of 230 patients, we found five patients with emphysema on CT scans, with no apparent cause. Therefore, we additionally analyzed the remaining 225 patients that were determined to be emphysema-free for excluding potential COPD. In the LAMA ( $n=94)$, LABA $(n=35)$, and LAMALABA ( $\mathrm{n}=96)$ groups, $\mathrm{FEV}_{1}$ values were increased by $0.100 \mathrm{~L}$ (SD, 0.208; $\mathrm{P}<0.001), 0.134 \mathrm{~L}$ (SD, 0.184; $\mathrm{P}<0.001)$, and $0.125 \mathrm{~L}$ (SD, 0.227; $\mathrm{P}<0.001$ ), respectively. Thus, we found meaningful results even after excluding five patients with emphysema (Appendix 1).

Among the 36 patients in the LABA group, only five were prescribed indacaterol alone, while others were prescribed LABA and inhaled corticosteroids. Therefore, we analyzed the five patients that were prescribed LABA alone using the Wilcoxon signed-rank test to compare $\mathrm{FEV}_{1}$ before and after treatment. The result showed a $\mathrm{P}$ value of 0.08 , which indicated no statistical significance but showed a trend toward improved lung function with treatment. Statistical significance may be achieved as the number of patients increases.

\section{Conclusions}

We found that treatment with bronchodilators such as LAMA or LABA was effective in improving lung function in patients with bronchiectasis. Such beneficial effects of bronchodilators were evident in patients who did not receive concurrent treatments that also improve lung function, thus supporting the use of LAMA and LABA in patients with bronchiectasis and warranting the need for a randomized controlled trial for confirmation.

\section{Acknowledgments}

We thank Dr. Joon Seo Lim from the Scientific Publications Team at Asan Medical Center for his editorial assistance in preparing this manuscript.

Funding: None.

\section{Footnote}

Data Sharing Statement: Available at http://dx.doi. org/10.21037/jtd-20-1282

Conflicts of Interest: All authors have completed the ICMJE uniform disclosure form (available at http://dx.doi. org/10.21037/jtd-20-1282). The authors have no conflicts of interest to declare.
Ethical Statement: The authors are accountable for all aspects of the work in ensuring that questions related to the accuracy or integrity of any part of the work are appropriately investigated and resolved. The study was conducted in accordance with the Declaration of Helsinki (as revised in 2013) and the Harmonized Tripartite Guideline for Good Clinical Practice from the International Conference on Harmonization. This study protocol was approved by the Asan Medical Center Institutional Review Board (approval number, 2019-0122). Informed consent was waived by the board due to the retrospective nature of the study.

Open Access Statement: This is an Open Access article distributed in accordance with the Creative Commons Attribution-NonCommercial-NoDerivs 4.0 International License (CC BY-NC-ND 4.0), which permits the noncommercial replication and distribution of the article with the strict proviso that no changes or edits are made and the original work is properly cited (including links to both the formal publication through the relevant DOI and the license). See: https://creativecommons.org/licenses/by-nc-nd/4.0/.

\section{References}

1. Polverino E, Goeminne PC, McDonnell MJ, et al. European Respiratory Society guidelines for the management of adult bronchiectasis. Eur Respir J 2017;50:1700629.

2. Choi H, Yang B, Nam H, et al. Population-based prevalence of bronchiectasis and associated comorbidities in South Korea. Eur Respir J 2019;54:1900194.

3. Seitz AE, Olivier KN, Adjemian J, et al. Trends in bronchiectasis among medicare beneficiaries in the United States, 2000 to 2007. Chest 2012;142:432-9.

4. Abo-Leyah H, Chalmers JD. New therapies for the prevention and treatment of exacerbations of bronchiectasis. Curr Opin Pulm Med 2017;23:218-24.

5. Hill AT, Sullivan AL, Chalmers JD, et al. British Thoracic Society guideline for bronchiectasis in adults. BMJ Open Respir Res 2018;5:e000348.

6. Jeong HJ, Lee H, Carriere KC, et al. Effects of long-term bronchodilators in bronchiectasis patients with airflow limitation based on bronchodilator response at baseline. Int J Chron Obstruct Pulmon Dis 2016;11:2757-64.

7. Cazzola M, Page CP, Calzetta L, et al. Pharmacology and therapeutics of bronchodilators. Pharmacol Rev 2012;64:450-504. 
8. Hong JY, Jung JY, Lee MG, et al. Changes in the prevalence of COPD in Korea between 2001 and 2011 in the KNHANES data. Respir Med 2017;125:12-8.

9. Miller MR, Hankinson J, Brusasco V, et al. Standardisation of spirometry. Eur Respir J 2005;26:319-38.

10. Choi JK, Paek D, Lee JO. Normal predictive values of spirometry in Korean population. Tuberc Respir Dis 2005;58:230-42.

11. Ismaila A, Corriveau D, Vaillancourt J, et al. Impact of adherence to treatment with tiotropium and fluticasone propionate/salmeterol in chronic obstructive pulmonary diseases patients. Curr Med Res Opin 2014;30:1427-36.

12. Kim JA, Lim MK, Kim K, et al. Adherence to Inhaled Medications and its Effect on Healthcare Utilization and Costs Among High-Grade Chronic Obstructive Pulmonary Disease Patients. Clin Drug Investig 2018;38:333-40.

13. Haupt D, Krigsman K, Nilsson JL. Medication persistence among patients with asthma/COPD drugs. Pharm World Sci 2008;30:509-14.

14. Briesacher BA, Andrade SE, Fouayzi H, et al. Medication adherence and use of generic drug therapies. Am J Manag Care 2009; 15:450-6.

15. Kerstjens HA, Rijcken B, Schouten JP, et. al. Decline of FEV1 by age and smoking status: facts, figures, and fallacies. Thorax 1997;52:820-7.

16. Sharma G, Goodwin J. Effect of aging on respiratory system physiology and immunology. Clin Interv Aging

Cite this article as: Lee SY, Lee JS, Lee SW, Oh YM. Effects of treatment with long-acting muscarinic antagonists (LAMA) and long-acting beta-agonists (LABA) on lung function improvement in patients with bronchiectasis: an observational study. J Thorac Dis 2021;13(1):169-177. doi: 10.21037/jtd-201282
2006;1:253-60.

17. Kim CJ, Yoon HK, Park MJ, et al. Inhaled indacaterol for the treatment of COPD patients with destroyed lung by tuberculosis and moderate-to-severe airflow limitation: results from the randomized INFINITY study. Int J Chron Obstruct Pulmon Dis 2017;12:1589-96.

18. Calverley PM, Burge PS, Spencer S, et al. Bronchodilator reversibility testing in chronic obstructive pulmonary disease. Thorax 2003;58:659-64.

19. Guan WJ, Gao YH, Xu G, et al. Bronchodilator response in adults with bronchiectasis: correlation with clinical parameters and prognostic implications. J Thorac Dis 2016;8:14-23.

20. Torén K, Bake B, Olin AC, et al. Measures of bronchodilator response of FEV1, FVC and SVC in a Swedish general population sample aged 50-64 years, the SCAPIS Pilot Study. Int J Chron Obstruct Pulmon Dis 2017;12:973-80.

21. Corhay JL, Dang DN, Van Cauwenberge H, et. al. Pulmonary rehabilitation and COPD: providing patients a good environment for optimizing therapy. Int J Chron Obstruct Pulmon Dis 2014;9:27-39.

22. Robson LS, Shannon HS, Goldenhar LM, et al. Guide to Evaluating the Effectiveness of Strategies for Preventing Work Injuries: How to Show Whether a Safety Intervention Really Works. National Institute for Occupational Safety and Health, 2001. 


\section{Supplementary}

Table S1 Baseline characteristics of patients without concurrent treatments (N=97)

\begin{tabular}{|c|c|c|c|c|}
\hline Characteristics & All patients & $\begin{array}{l}\text { Treatment with } \\
\text { LAMA }\end{array}$ & Treatment with LABA & $\begin{array}{l}\text { Treatment with } \\
\text { LAMA-LABA }\end{array}$ \\
\hline Number of patients & 97 & 45 & 17 & 35 \\
\hline Male sex, \% & $34(35.1 \%)$ & $16(35.6 \%)$ & $6(35.3 \%)$ & $12(34.30 \%)$ \\
\hline Body mass index ${ }^{\mathrm{a}}, \mathrm{kg} / \mathrm{m}^{2}$ & $23(21.3-25.3)$ & $22.8(21.3-25.3)$ & $22.8(20.2-23.9)$ & $24(21.5-27.2)$ \\
\hline 0 & $38(39.2 \%)$ & $18(40 \%)$ & $11(64.7 \%)$ & $9(25.7 \%)$ \\
\hline 1 & $38(39.2 \%)$ & $22(48.9 \%)$ & $4(23.5 \%)$ & $12(34.3 \%)$ \\
\hline 2 & $11(11.3 \%)$ & $4(8.9 \%)$ & $1(5.9 \%)$ & $6(17.1 \%)$ \\
\hline Past tuberculosis infection & $20(20.6 \%)$ & $9(20 \%)$ & $4(23.5 \%)$ & $19(19.2 \%)$ \\
\hline Past or current NTM infection & $11(11.3 \%)$ & $4(8.9 \%)$ & $2(11.8 \%)$ & $11(11.1 \%)$ \\
\hline \multicolumn{5}{|l|}{ Extrapulmonary comorbidities } \\
\hline Hypertension & $29(29.9 \%)$ & $10(22.2 \%)$ & $6(35.3 \%)$ & $34(34.3 \%)$ \\
\hline Diabetes mellitus & $18(18.6 \%)$ & $7(15.6 \%)$ & $5(29.4 \%)$ & $14(14.1 \%)$ \\
\hline Cardiocerebrovascular disease & $4(4.1 \%)$ & $2(4.4 \%)$ & $1(5.9 \%)$ & $9(9.1 \%)$ \\
\hline Chronic kidney disease & $3(3.1 \%)$ & $0(0 \%)$ & $1(5.9 \%)$ & $5(5.1 \%)$ \\
\hline $\mathrm{FEV}_{1} / \mathrm{FVC}$ & $0.608 \pm 0.11$ & $0.635 \pm 0.086$ & $0.653 \pm 0.128$ & $0.56 \pm 0.12$ \\
\hline
\end{tabular}

Data are presented as numbers (\%) unless specified otherwise. ${ }^{\text {a }}$, median(interquartile range); ${ }^{\mathrm{b}}$, mean \pm standard deviation. LAMA, long-

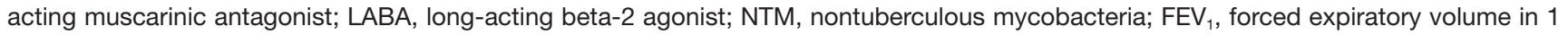
second; FVC, forced vital capacity. 


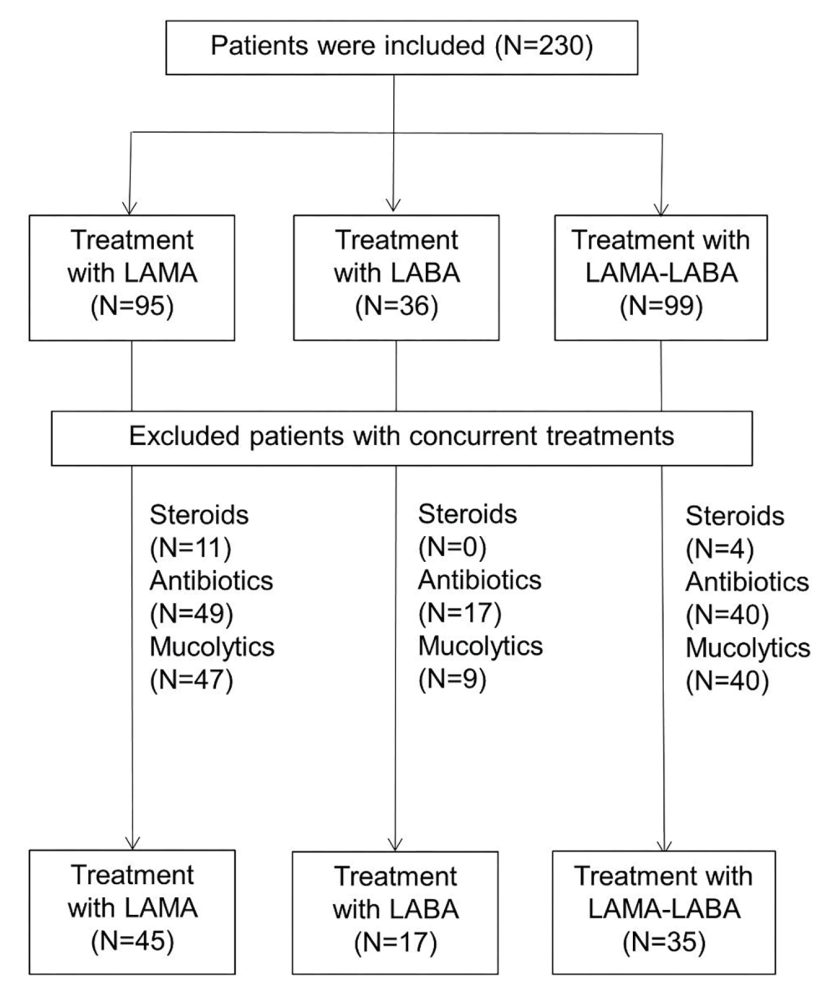

Figure S1 Patients selection flow after excluding patients treated with other medications. LAMA, long- acting muscarinic antagonist; LABA, long-acting beta-agonists.
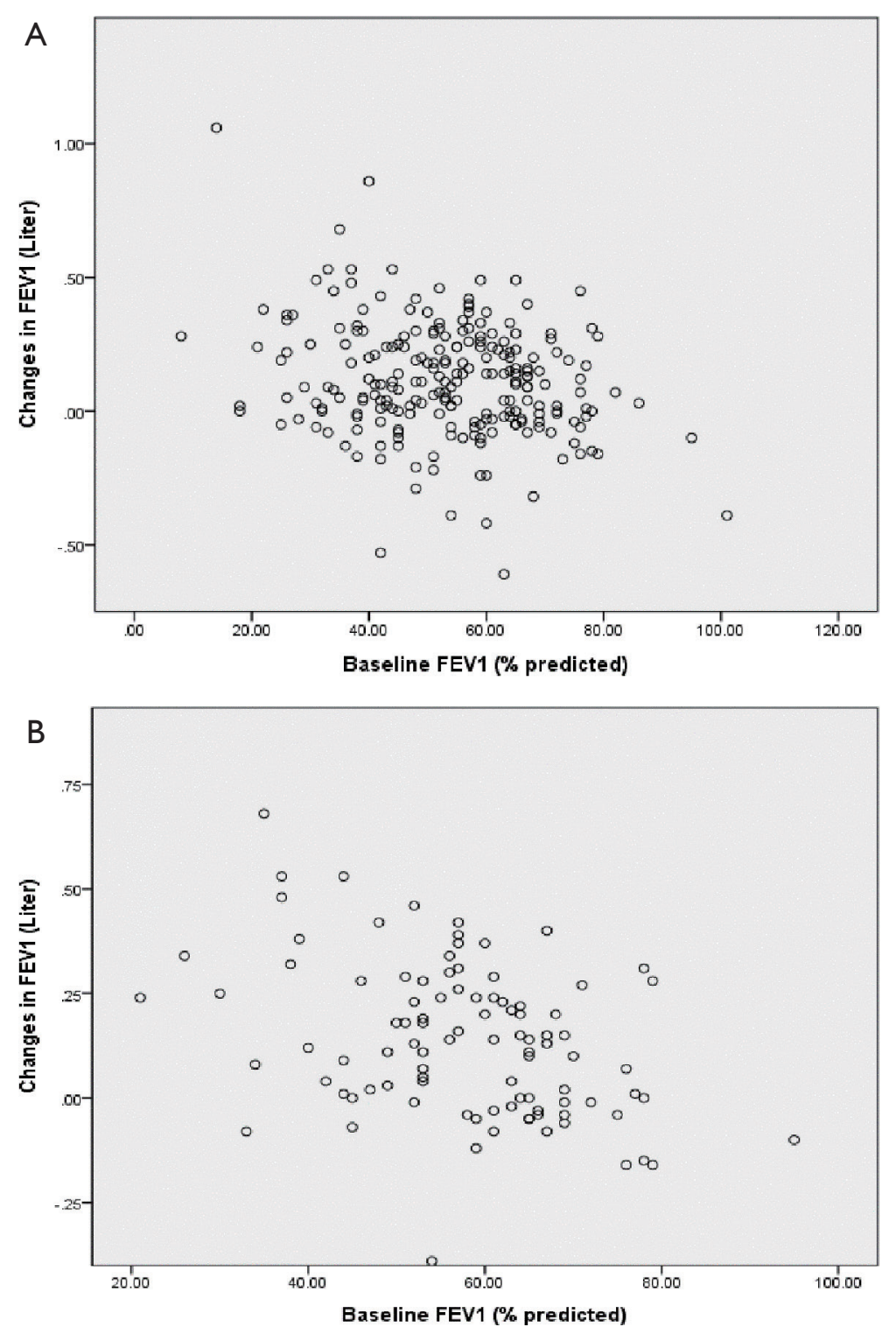

Figure S2 Scatter plot of baseline FEV1 and FEV1 changes after LAMA, LABA or LAMA-LABA treatment in (A) all patients (N=230, $\mathrm{R}=-0.242, \mathrm{P}<0.001)$ and $(\mathrm{B})$ patients without concurrent treatments $(\mathrm{N}=97, \mathrm{R}=-0.386, \mathrm{P}<0.001) . \mathrm{FEV}_{1}$, forced expiratory volume in 1 second; LAMA, long-acting muscarinic antagonist; LABA, long-acting beta-agonists. 
Appendix 1 The CT scans of five patients with emphysema

$<$ Patient 1>

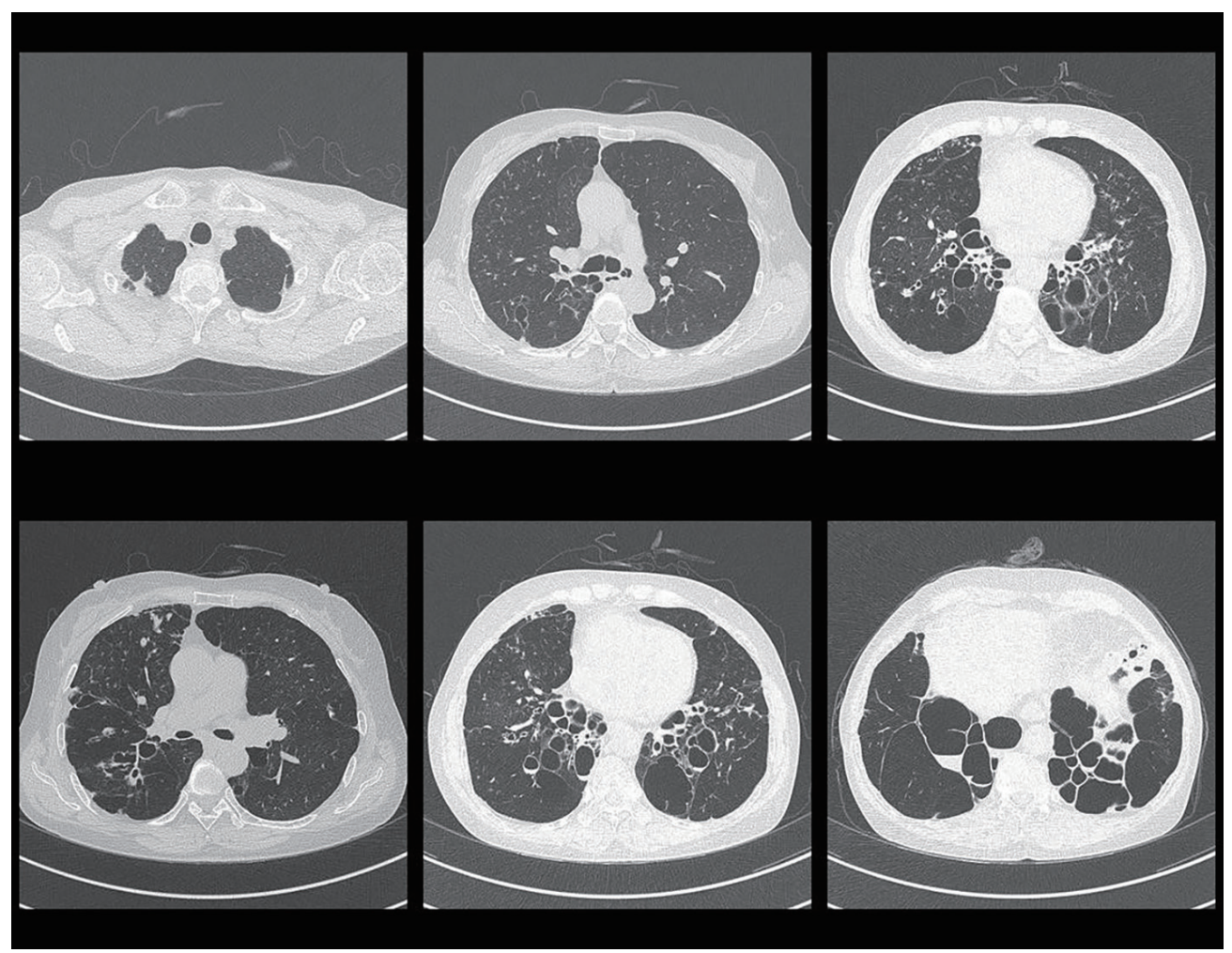

$<$ Patient 2>

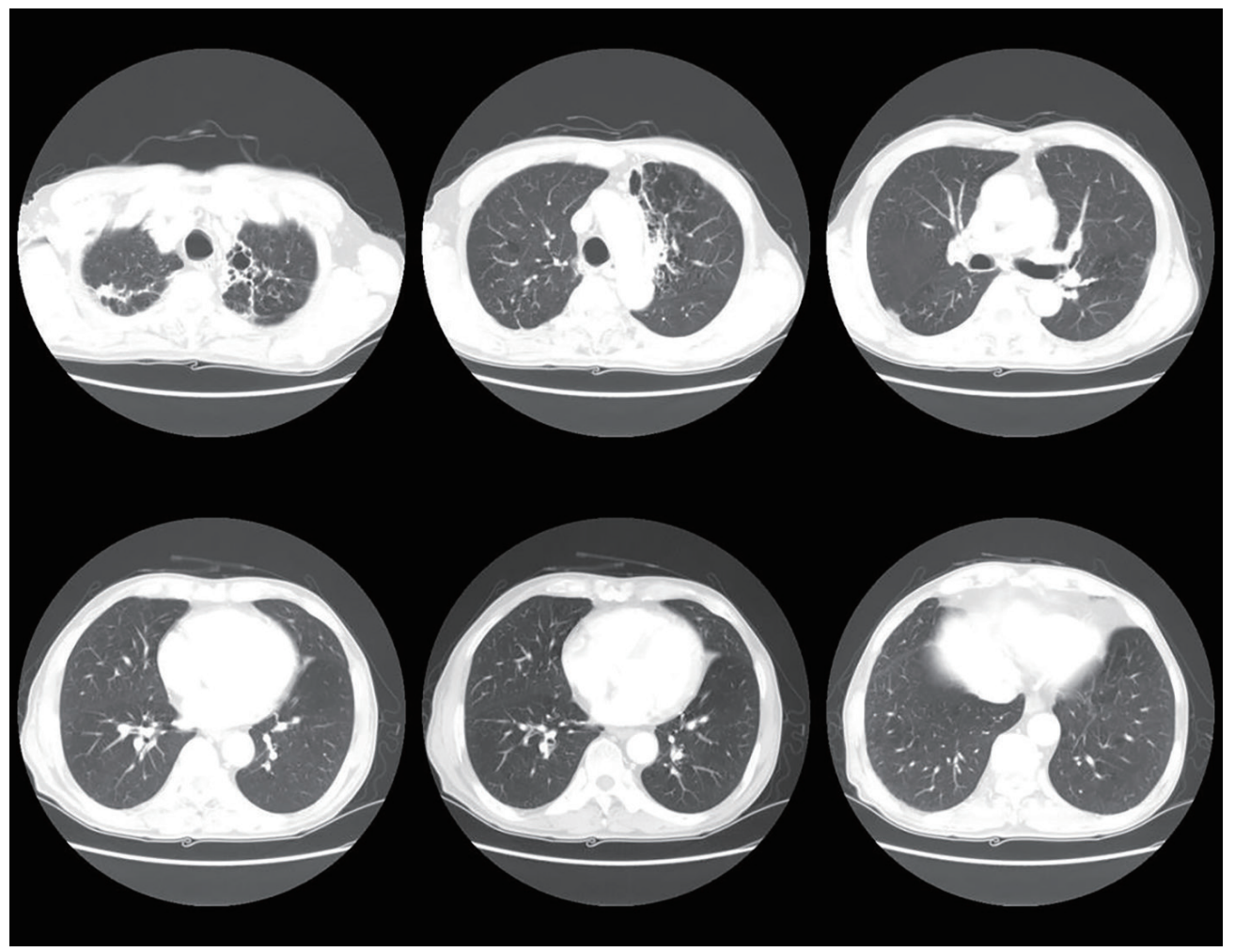




\section{$<$ Patient 3>}

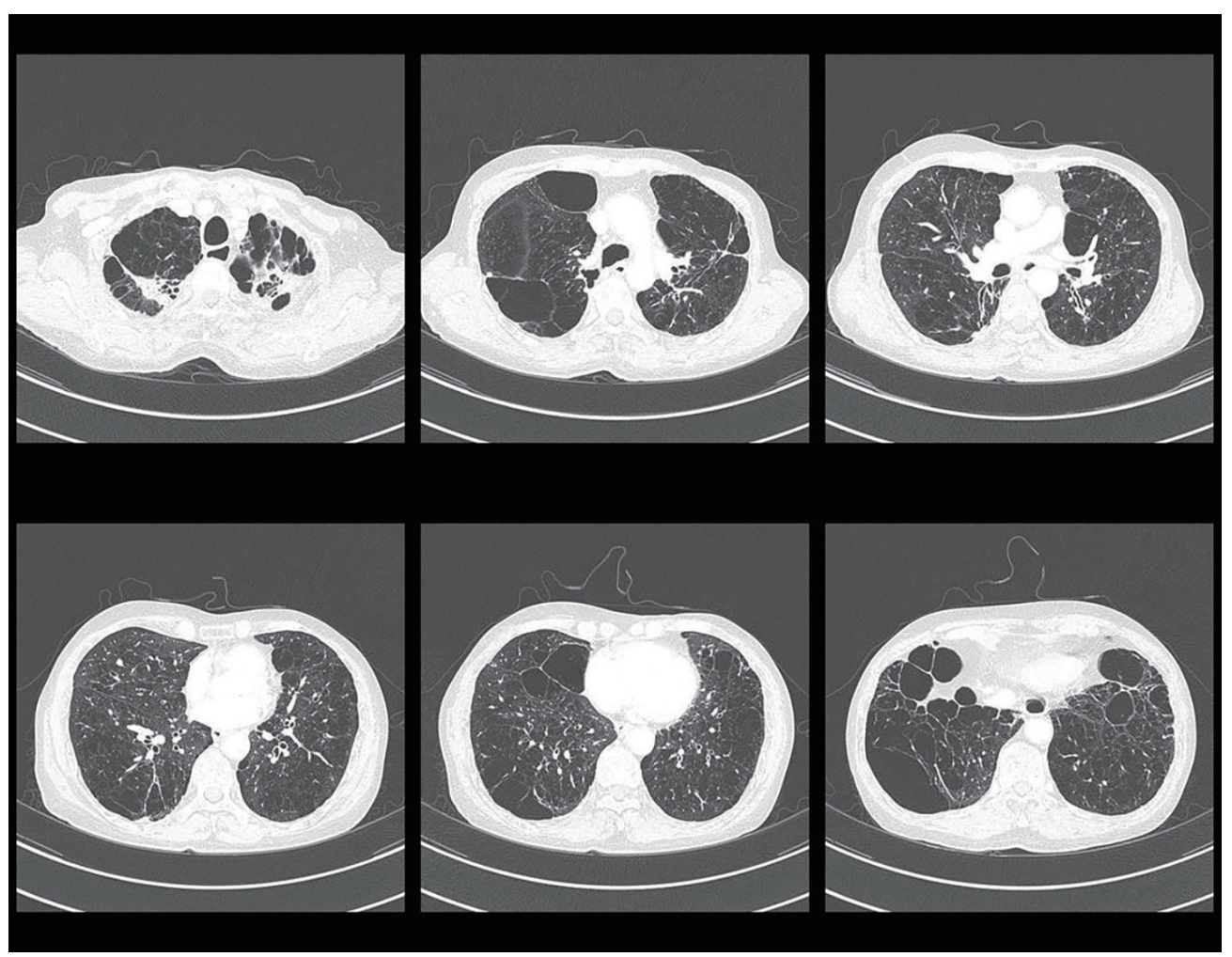

$<$ Patient 4>

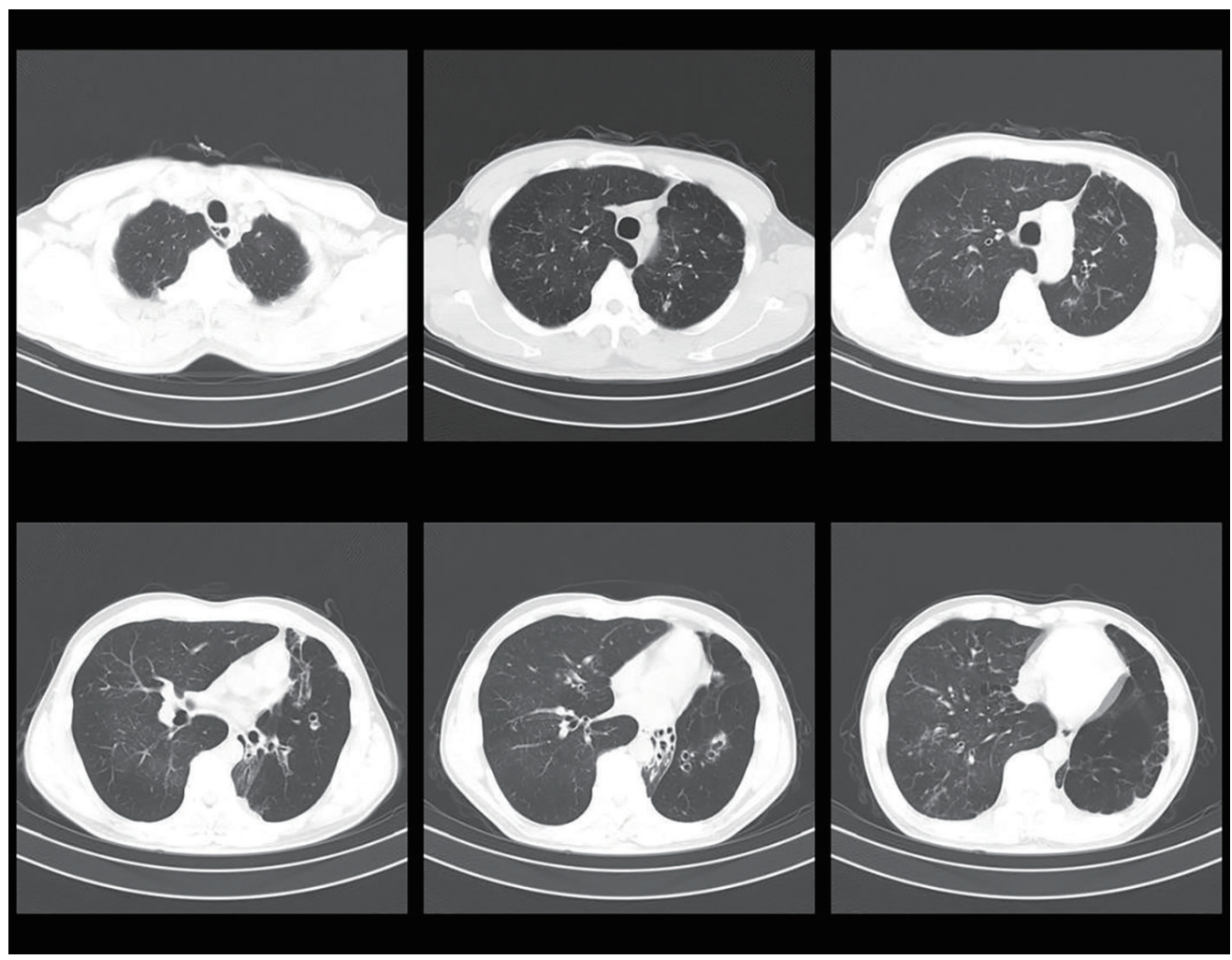

(c) Journal of Thoracic Disease. All rights reserved. 
$<$ Patient 5>

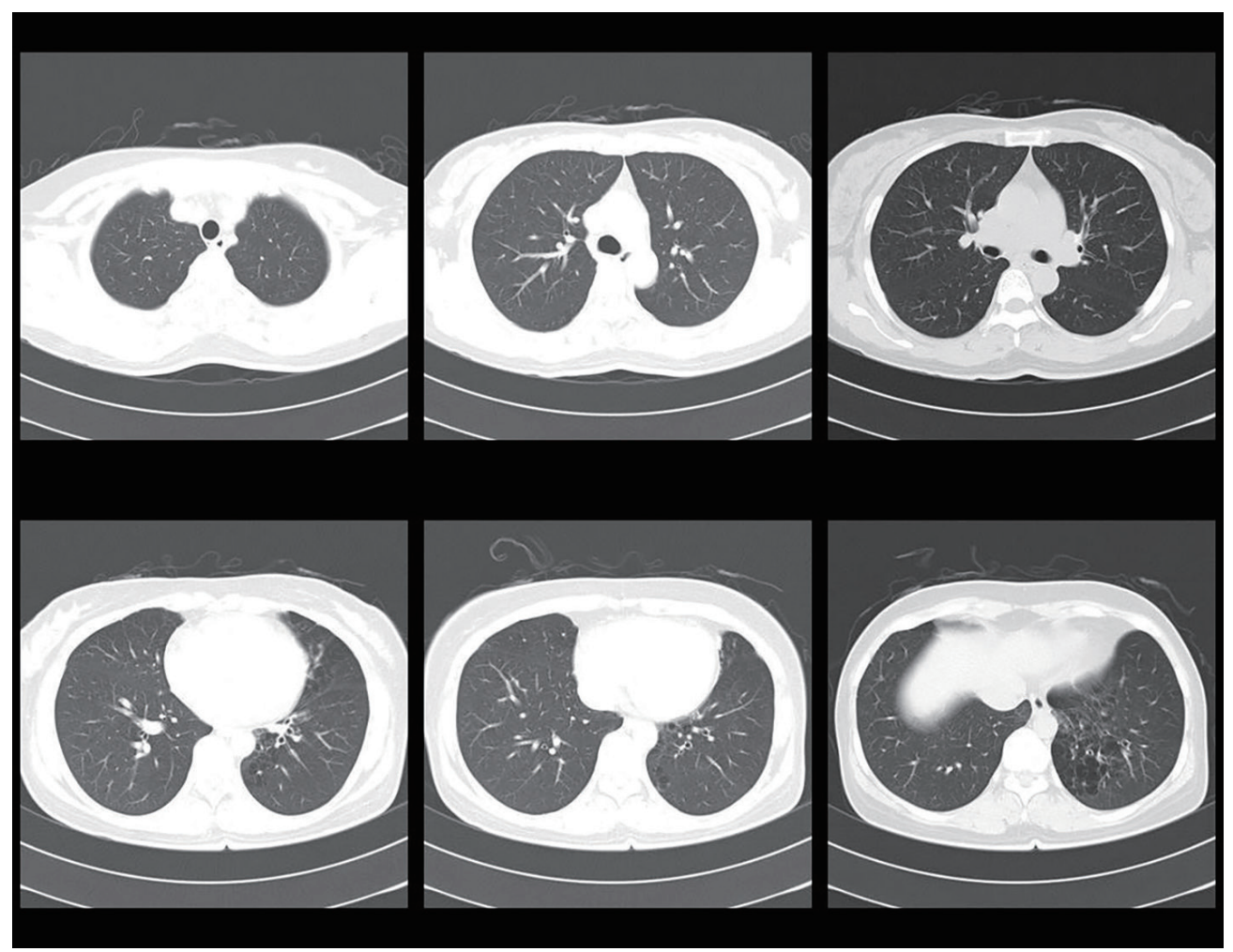

